\title{
A CRIAÇÃO DOS CLUBS NAS PRAÇAS PÚBLICAS DA CIDADE DE PORTO ALEGRE (1920-1940)
}

\author{
MS. MARIA LUISA OLIVEIRA DA CUNHA \\ Mestre em Ciências do Movimento Humano pela UFRGS e \\ Professora Assistente do Depto. de Educação Física da \\ Universidade Federal do Rio Grande do Sul (Rio Grande do Sul - Brasil) \\ e-mail: maluoliveira@ufrgs.br \\ DRA. JANICE ZARPELLON MAZO \\ Doutora em Ciências do Desporto pela Universidade do Porto e \\ Professora Ajunta do Depto. de Educação Física da \\ Universidade Federal do Rio Grande do Sul (Rio Grande do Sul - Brasil) \\ e-mail: janmazo@terra.com.br
}

\section{RESUMO}

A propagação das práticas esportivas nas praças públicas de Porto Alegre na década de 1920 e as melhorias instauradas nesses espaços visando a promover a sociabilidade e o lazer favoreceram a criação dos clubs das praças. O objetivo do estudo é identificar como ocorreu a emergência dos clubs nas praças públicas da cidade de Porto Alegre. Os procedimentos metodológicos de análise documental de fontes impressas revelaram que os clubs formados nas praças construíram representações similares às associações esportivas. A organização de equipes, a elaboração de estatutos, a adoção de flâmulas e a participação em competições esportivas são exemplos de representações e práticas culturais estabelecidas pelos clubs nas praças.

PALAVRAS-CHAVE: Praças e clubes; história; esporte e lazer. 
O presente estudo trata dos clubs organizados nas praças públicas da cidade de Porto Alegre na década de 1920 e que se mantiveram em atividade até a década de 1940. Até a década de 1920, as práticas esportivas eram realizadas nas associações ou sociedades. Nesse período, gradualmente, ocorre o alargamento da prática esportiva para algumas praças públicas da cidade, que se afirmaram enquanto espaços para a sociabilidade e o lazer.

As primeiras praças públicas de Porto Alegre surgiram no final do século XIX, mas somente no início do século $X X$ começaram, aos poucos, a ser ocupadas pelos porto-alegrenses para a sociabilidade e o lazer. As formas de ocupação dessas praças foram sendo reformuladas em decorrência das transformações políticas, econômicas e sociais desencadeadas no final do século XIX.

A prática dos lazeres ocorreu como uma das consequências da Revolução Industrial, não apenas no cenário nacional, mas em um quadro ocidental, onde vemos a sociedade utilizando seu tempo livre em diversas práticas culturais. Essa nova situação mundial implicou outro olhar sobre as praças de Porto Alegre, espaços que, inicialmente, eram destinados apenas aos passeios dos porto-alegrenses. Com a transformaç̧ão do significado das praças e a sua apropriação pela população, outras formas de lazer começaram a emergir, destacando-se as práticas esportivas.

incremento da prática do esporte e a criação do Serviço de Recreação Pública (SRP) da cidade de Porto Alegre em 1926 repercutiram na ocupação de algumas praças com o intuito de fomentar o esporte. Nesse sentido, os espaços escolhidos foram denominados Praças de Desportos e, à medida que começaram a ser utilizadas pelas escolas, constituindo-se em uma extensão das mesmas, passaram a ser chamados Praças de Educação Física, contando com o trabalho de instrutores de Educação Física. Nessas Praças de Desportos e de Educação Física, desencadeou-se a formação dos chamados clubs, ou seja, a formação de equipes esportivas com a finalidade de representar as praças nas competições citadinas.

Assim, o objetivo do presente estudo é identificar como ocorreu a constituição dos clubs nas praças públicas de Porto Alegre no período compreendido entre os anos 1920 a 1940. Desse objetivo central, emergem as seguintes questões norteadoras da pesquisa: (a) Como funcionaram os clubs das praças públicas de Porto Alegre nos anos de 1920 a 1940? (b) Quais as práticas esportivas fomentadas pelos clubs das praças? (c) Que práticas e representações culturais de identidades foram construídas pelos clubs nas praças públicas de Porto Alegre nos anos de 1920 a 1940 ?

Justifica-se a realização desta pesquisa em razão de se perceber que os estudos que tratam do lazer e da recreação públicos em Porto Alegre (AMARAL, 
1998; AMARAL, 200 I; FEIX, 2003; MAZO, 2004; WERNECK, 2002), em geral, focalizam apenas o período da segunda metade dos anos 1920, quando iniciaram as atividades recreativas nas praças públicas de Porto Alegre e o Serviço de Recreação Pública. Há uma lacuna, portanto, no que diz respeito à difusão das práticas corporais e esportivas nas praças e parques públicos nas décadas seguintes. Assim, esta pesquisa, que resulta da dissertação de mestrado elaborada por Cunha (2009)', busca contribuir para alargar os estudos históricos das práticas corporais e esportivas no estado do Rio Grande do Sul, bem como possibilitar, futuramente, a realização de estudos comparativos.

\section{PROCEDIMENTOS METODOLÓGICOS}

Os procedimentos metodológicos adotados foram coleta e análise de fontes impressas por meio da análise de conteúdo (BARDIN, 1977; TRIVIÑOS, 1992). A análise de conteúdo é uma operação ou um conjunto de operações que visa a representar o conteúdo de um documento sob uma forma diferente da original, a fim de facilitar, em um estado ulterior, sua consulta e referenciação. Enquanto tratamento da informação contida nos documentos acumulados, a análise tem por objetivo dar forma conveniente e representar de outro modo essa informação, por intermédio de procedimentos de transformação.

A pesquisa documental percorreu diversas fontes históricas sobre a formação e a organização dos clubs nas praças da cidade de Porto Alegre no período de 1920 a 1940, a saber: a) Catálogo Esporte e Educação Física na Revista do Globo (MAZO, 2004); b) Almanaque Esportivo do Rio Grande do Sul, organizado por José Ferreira Amaro Júnior no período de 1942 a 1959; e c) acervo do Centro de Memória do Esporte (CEME) da ESEF/UFRGS, onde encontramos material catalogado sobre recreação pública, advindo, em grande parte, de doações de familiares dos personagens envolvidos nesse momento histórico da cidade de Porto Alegre. Além das fontes históricas mencionadas, subsidiaram a pesquisa bibliográfica dissertações, monografias, teses, livros e outros documentos, tais como mapas, plantas baixas, projetos arquitetônicos e legislação. Tal documentação também contribuiu para o aporte teórico e a análise dos dados da investigação.

Para transitar pela história que esse passado nos revela na cidade de Porto Alegre nas décadas de 1920 a 1940, as bases teórico-metodológicas do estudo

I. Dissertação esta que está inserida em um dos eixos de um projeto mais amplo, denominado "Esporte e Educação Física no Rio Grande do Sul: estudos históricos", do Núcleo de Estudos em História e Memória do Esporte e da Educação Física (NEHME), da Escola da Educação Física (ESEF) da Universidade Federal do Rio Grande do Sul (UFRGS). 
foram sustentadas pelos seguintes autores: Roger Chartier (1990; 199|), Peter Burke (2005) e Norbert Elias (1992a; 1992b). Chartier (1990; 1991) e Burke (2005), embora com algumas posições distintas, contribuíram para um olhar sobre o objeto de estudo na perspectiva da história cultural, procurando identificar o modo como os clubs esportivos foram arquitetados na sociedade porto-alegrense daquele período, considerando-os enquanto um fenômeno cultural, que se manifesta por meio de práticas que produzem representações culturais, as quais, por sua vez, podem desencadear práticas culturais.

De acordo com esse horizonte teórico, as mais diversas formações culturais podem ser examinadas no âmbito produzido pela relação interativa entre os pólos: práticas e representações. Tanto os objetos culturais seriam produzidos entre práticas e representações, como os sujeitos produtores e receptores de cultura circulariam entre esses dois pólos. A representação, acrescenta Chartier ( 199 |), insere-se em um campo de concorrências e competições cujos desafios enunciam-se em termos de poder e dominação; em outras palavras, são produzidas verdadeiras lutas de representações. Essas lutas, segundo o autor, geram inúmeras apropriações possíveis das representações, de acordo com os interesses sociais, com as imposições e resistências políticas, e com as motivações e necessidades que se confrontam no mundo humano. O trabalho de Elias ( 1992b) aborda as práticas ordinárias, "sem qualidades", que tecem a trama das relações cotidianas e exprimem a maneira como uma comunidade, em um tempo e um lugar determinados, vive e reflete sua relação com o mundo e a história.

A riqueza de estudar e escrever a história de um determinado acontecimento está na possibilidade criativa, investigatória e no olhar não-convencional da linearidade e das fontes tradicionais. A sensibilidade do pesquisador e o seu referencial teórico é que vão direcionar várias perspectivas de um texto mais comprometido com os contextos social, econômico e cultural da época em pauta. Fazer história da história é uma arte e um grande desafio, pois o pesquisador terá de se comprometer com o estudo do ser humano no tempo, entender as suas representações de mundo, verificar a sua cultura, além de levantar os fatos e as obras de um tempo que não viveu, mas que deixou seus vestígios (BURKE, 2005).

Nesse sentido, procurou-se, neste trabalho, desenvolver uma narrativa, como bem afirma Peter Burke (2005), centrada na preocupação em analisar os contextos socioculturais que envolvem as pessoas comuns, salientando as maneiras pelas quais elas aplicavam sentido às suas práticas e aos seus mundos.

\section{OS CLUBS DAS PRAÇAS PÚBLICAS DE PORTO ALEGRE}

Nas décadas de 1920 a 1940, a disseminação de um ideário de modernidade reorganizou as relações sociais na cidade de Porto Alegre, por meio das obras de 
remodelação que foram impulsionadas pelo desenvolvimento econômico. A fisionomia da cidade começou a ser alterada em função das significativas intervenções urbanas desencadeadas na década de 1920 e acentuada na década seguinte, especialmente no tocante à ampliação da destinação de espaços públicos às atividades de lazer para a população porto-alegrense. De lado a lado, observavam-se, no espaço urbano, obras de saneamento, alargamento de ruas, embelezamento da cidade, construção de prédios públicos e mudanças em praças e parques. Parece que havia a preocupação, por parte das autoridades da Intendência, então Governo Municipal, de melhorar as condições de vida dos porto-alegrenses, por meio da construção de algumas praças ou da apropriação de outros espaços públicos para fins de lazer.

A necessidade e o interesse de investimento institucional em educação, esporte e recreação eram prementes, influenciados pelo movimento de educação física mundial, que poderia ser um meio de prevenção da delinquência juvenil. Além disso, a conquista de maior tempo livre pelos trabalhadores, a carência de lugares públicos para crianças brincarem e a existência de instrutores disponíveis nas praças para viabilizar a prática de esportes, conferiam a esses espaços o status de lugar adequado para esses fins. Dessa forma, as praças deveriam ser dotadas de equipamentos apropriados e de recursos humanos que organizassem as práticas corporais e esportivas que ali seriam desenvolvidas. As relações sociais se dariam nesses locais no tempo livre do trabalho e da escola, e a importância de tais ocasiões e da direção das ações que seriam realizadas começaram a despertar na municipalidade a intenção de controle. Nesse caminho, as praças são vislumbradas como possibilidade de ocupação do tempo livre, e a direção das ações nesses espaços aparece como função inerente à municipalidade. Para cumprir seu papel, o Governo Municipal criou, em 1926, o Serviço de Recreação Pública da Prefeitura Municipal de Porto Alegre.

O Serviço de Recreação Pública foi idealizado pelo Prof. Frederico Guilherme Gaelzer, então primeiro inspetor de Educação Física da Diretoria Geral da Instrução Pública do estado do Rio Grande do Sul. O professor Gaelzer é considerado o pioneiro da institucionalização da recreação pública em Porto Alegre, pois programou e implantou os Jardins de Recreio, também chamados Praças de Recreio e, mais tarde, as Praças de Desportos em algumas praças públicas da cidade. Cabe destacar, ainda, que Gaelzer foi professor pioneiro da primeira instituição de ensino superior em Educação Física no Rio Grande do Sul, criada em 1940 - a Escola Superior de Educação Física, atual ESEF/UFRGS - e atuou como diretor dessa instituição no período de 28/09/I 955 a 24/02/I959 (GUTIERREZ, I 97 I).

A organização das Praças de Desportos empreendida pelo professor Gaelzer era notável. Para facilitar seu controle e sua própria fiscalização, todos os frequentadores assíduos eram registrados e classificados em categorias. Segundo as anotações 
e os relatórios encontrados no álbum de artigos intitulado Recreação Pública² que integra o acervo do CEME/ESEF/UFRGS, a seção feminina estava dividida em meninas e moças; e a seção masculina, em três categorias: meninos (de 12 a 14 anos), rapazes ( 15 a 17 anos) e moços ( 8 a 25 anos). A partir dessa categorização, o professor Gaelzer estimulava a composição de clubs esportivos em cada praça, com a intenção de que estes participassem dos campeonatos organizados pelo Serviço de Recreação Pública.

A forma de organização das atividades nas praças ficou registrada nos seus programas impressos, que continham um roteiro dos acontecimentos planejados. Para exemplificar a programação de atividades voltadas aos menores - meninos e meninas -, listamos os jogos e as brincadeiras desenvolvidos: corrida em 75 metros, capitão soldado ladrão, corrida em pneus, jogo das batatas, círculo, salto em distância e cabo de guerra. Já na categoria rapazes, as atividades eram voltadas aos moldes esportivos como, por exemplo, corrida em 100 metros, salto em distância, lançamento de bola, entre outras. E, para a categoria moças, as atividades previstas eram corridas de agulhas e de velas, descrição condizente com a preservação de sua feminilidade, apesar da prova. Todas as atividades eram dedicadas a homenagear personalidades da capital. Fato interessante é que, nesses roteiros, as dedicatórias sempre vinham seguidas simplesmente do nome a honrar; entretanto, em um dos panfletos de divulgação, chamou-nos a atenção, na terceira modalidade para rapazes - "lançamento de bola" - a seguinte frase: "dedicada ao esforçado Director da Praça, Sr. Guilherme Gaelzer".

Nesse mesmo documento, encontramos o anúncio do Torneio de Volley-ball disputado entre os times das praças Jahú e Sul América, e Bataclan e Florida. Com base nesses programas e nas publicações de jornais encontrados no CEME/ESEF/ UFRGS, as pesquisadoras organizaram um quadro em se encontram relacionados clubs formados nas Praças de Desportos, as quais também possuíam Jardins de Recreio (CUNHA, 2009, p. 72):

2. Esse álbum contém uma série de recortes de jornais porto-alegrenses, do Brasil e também do exterior (Uruguai e Estados Unidos), os quais trazem reportagens sobre o trabalho do professor Frederico Guilherme Gaelzer. Os jornais encontrados foram os seguintes: A Notícia; Correio do Povo; e Última Hora (atual Zero Hora). Estes, geralmente, destacavam notícias sobre as praças e os parques, incluindo as mudanças em sua infraestrutura. Tal documentação foi doada pela também professora Lenea Gaelzer, filha do professor Gaelzer, ao CEME/ESEF/UFRGS, juntamente com um vasto material composto por fotos, documentos e plantas arquitetônicas que se referiam ao trabalho executado pelo professor Gaelzer na cidade de Porto Alegre e nos países onde estudou e trabalhou. Esse acervo não possui registro catalográfico; por esse motivo, a partir deste momento, o citaremos como Álbum Recreação Pública do acervo do CEME/ESEF/UFRGS. 
Quadro I. Praças de Desportos e Jardins de Recreio com seus respectivos clubs.

\begin{tabular}{|c|c|}
\hline Nome das Praças de Desportos e Jardins de Recreio & Nome dos clubs \\
\hline \multirow{5}{*}{$\begin{array}{l}\text { Praça General Osório ou Praça do Alto da Bronze - Jardim } \\
\text { de Recreio n }\end{array}$} & Club Atléthico Marechal Deodoro \\
\hline & Athlético General Osório \\
\hline & Grupo dos Solteirões Honestos \\
\hline & Grupo Atléthico Jovial \\
\hline & Gaúcho Volley-ball Club \\
\hline \multirow{4}{*}{ Praça Pinheiro Machado - Jardim de Recreio $n^{\circ} 2$} & Grêmio Atléthico Cruzeiro do Sul \\
\hline & Atléthico Rio-Grandense \\
\hline & Atléthico Botafogo \\
\hline & Atléthico General Pinheiro Machado \\
\hline \multirow{5}{*}{ Praça Florida - Jardim de Recreio n 3} & Atléthico Flamengo \\
\hline & Bataclan Volley-ball Club \\
\hline & Florida Volley-ball Club \\
\hline & Jahú Volley-ball Club \\
\hline & Esportivo Sul América \\
\hline
\end{tabular}

Os clubs eram formalmente criados por jogadores e registrados no Serviço de Recreação Pública. Depois de instituídos os clubs, era escolhida a diretoria e organizada a forma de funcionamento. Os registros de fundação eram divulgados pelos jornais locais, assim como seus atos, comunicados de assembleias, nova diretoria e datas das competições esportivas. Um exemplo disso são o cartaz e o ofício comunicando a criação do Bataclan Wolley-ball Club, que representava a Praça de no 3 - Praça Florida, datado de 24 de julho de 1927, o mesmo ano da criação dessa praça. 


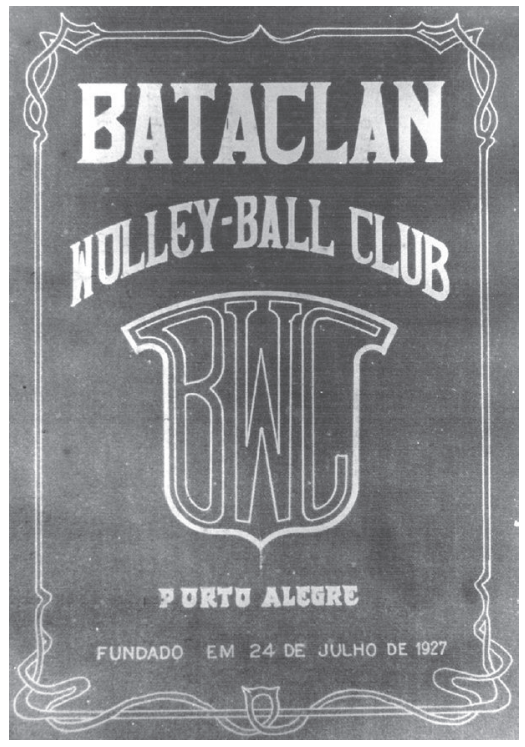

Ilustração I. Cartaz do Bataclan Wolley-ball Club, fundado em 24 de julho de 1927. Fonte: Acervo do CEME/ ESEF/UFRGS - Álbum Recreação Pública.

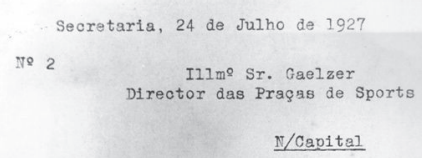

Terho a subida honrs de communicarevos que, nesta data, foi fundado, por elementos da Praça de Sports Florida, nesta capital, 0 BATACLAN \#OTT TY-BALI CIUB, para o cultivo do wolley-ball. Eeporamos pois, do digno Director das Pra ças de Sports da Municipalidade, todo o valioso apoio que the seculiar, para o desenvolvimento apoio que the pecu

A Direotoria que deverá reger os destinos do Bataclan, no anno social 1927-28, loi assim constituida:

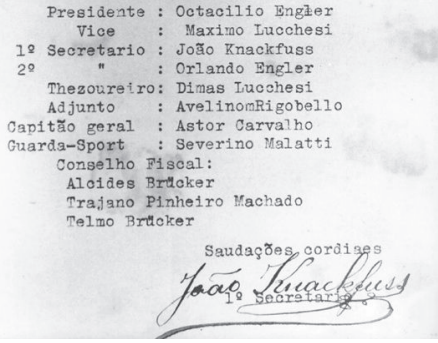

Ilustração 2. Ofício de fundação do Bataclan Wolley-ball Club em 27 de julho de 1927. Fonte: Acervo do CEME/ESEF/ UFRGS - Álbum Recreação Pública.

A publicação de notícias sobre os clubs em jornais permitiu garimpar informações sobre a assembleia de fundação de dois clubs na mesma praça, a General Osório: Club Athlético General Osório e Gaúcho Wolley-ball Club. Seguem no quadro abaixo os cargos que compunham a diretoria dos clubs, mostrando sua organização no ato de fundação:

Quadro 2. Relação de dirigentes dos clubs Gaúcho Wolley-ball Club e Club Athlético General Osório da Praça General Osório (CUNHA, 2009, p. 75).

\begin{tabular}{|l|l|l|}
\hline & Club Athlético General Osório & Gaúcho Wolley-ball Club \\
\hline Nome da Praça & General Osório & General Osório \\
\hline Presidente & Wilson Freitas Maciel & Macahé Contreiras \\
\hline Vice-Presidente & Miguel de Castro Martins & Neolon Pio da Silva \\
\hline Período da gestão & $22 / 08 / 1929$ a 22/08/1930 & Não encontrado \\
\hline Secretário & Paulo Soares & J. M. Kaenzel \\
\hline Tesoureiro & Pedro Caputti & Felix Goya \\
\hline Capitão Geral & Antonio Silva & Emilio Stoll \\
\hline Capitão de Team & Luiz Romano & Lourival Zanini \\
\hline
\end{tabular}

O voleibol, como foi possível observar no Quadro 2, que mostra a criação de um club dessa prática esportiva, já tinha muitos adeptos em Porto Alegre. Pela iniciativa do professor Gaelzer, foi organizado o Campeonato Municipal de Wolley-ball na cidade. 
Esse campeonato, disputado em duas categorias, rapazes e moças, aceitava a inscrição de somente uma equipe por praça; por esse motivo, foram realizadas eliminatórias entre os clubs, a fim de ser apurado o campeão de cada praça, o qual disputaria a prova final no campeonato municipal. Aquilatamos a importância desse evento quando encontramos, em publicação de jornal da época, a menção sobre a entrega da premiação aos vencedores, com a presença do próprio Intendente Municipal, Dr. Octavio Rocha.

Além do campeonato de voleibol, muitos outros eventos esportivos foram realizados nas praças, dentre os quais destacamos estes: Campeonato Popular de Basquete (1938); Torneio Universitário de Football (1938); Torneio de Basquete e Vôlei da Praça Dr. Montaury (1938); Grande Corrida Rústica da "Semana da Pátria" ( 1939$) ;$ Programa de Recreação na Praça Pinheiro Machado em homenagem aos garotos vendedores de jornais (1938/I 939); e Torneio de Vôlei Feminino (1940) (PIMENTEL, 1945; MAZO, 2007). Essas diversas competições remetem-nos ao entendimento de que as práticas corporais e esportivas, constituídas como modernas atividades de lazer, cumpriam seu papel liberando as tensões do estresse cotidiano, permitindo as manifestações de sentimentos, e resguardando a integridade física e moral das pessoas dentro da ordem imperante (ELIAS, 1992a).

Imagens encontradas dos clubs formados nas praças chamaram-nos a atenção para alguns detalhes. Os integrantes perfilados seguravam as flâmulas que, com as inscrições "Praça número 2" e "Praça número 3", delimitam seu espaço. Percebe-se que aquela ação registrada nas fotografias deixava saber as seguintes informações: a que ou a quem eles representavam; quem eram; de onde vinham; e por quem jogavam. Chartier (1990, p. 20) expõe-nos uma das funções da representação como "exibição de uma presença, como apresentação pública de algo"; e é nesse sentido que os clubs das praças e suas práticas, enquanto atividades sociais produtoras de significados e sentidos, revelavam-se independentes e providos de uma lógica inerente ao contexto social em que eram produzidas (WAGNER, 1998).

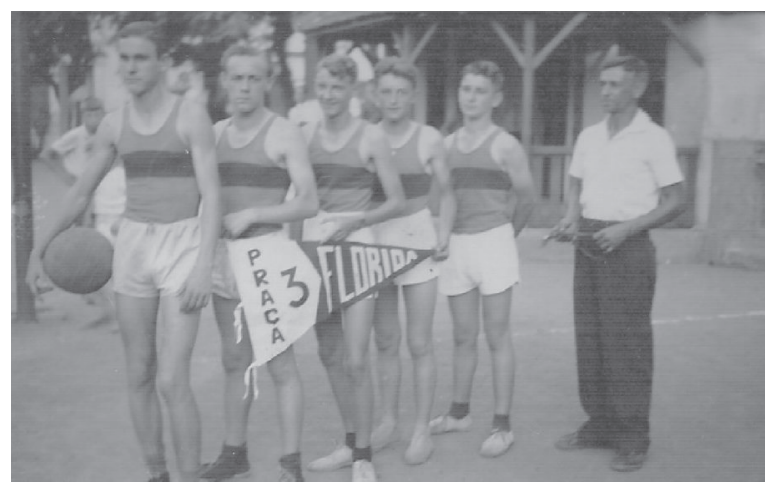

Ilustração 3. Club de Basquetebol da Praça n 3 Florida.

Fonte: Álbum Recreação Pública do acervo do CEME/ESEF/UFRGS. 


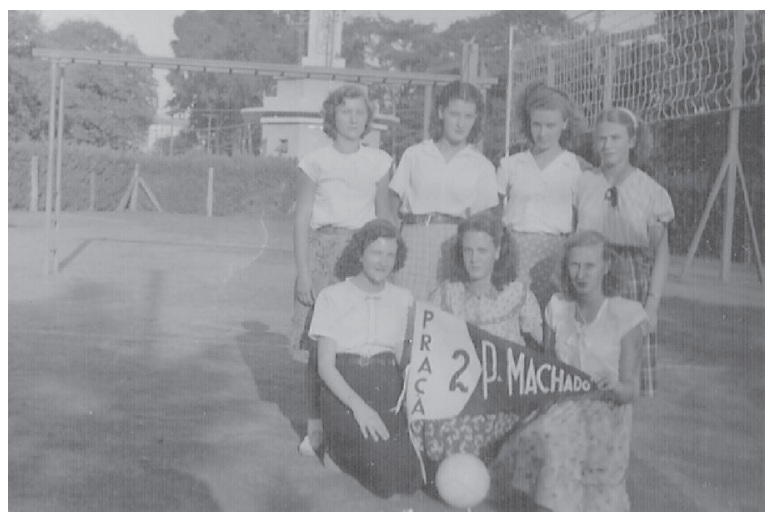

Ilustração 4. Club de Voleibol da Praça nº 2 Pinheiro Machado.

Fonte: Álbum Recreação Pública do acervo do CEME/ESEF/UFRGS.

A proposta de organização de clubs nas praças, conforme os exemplos mencionados acima, estava latente desde a criação das primeiras Praças de Desportos na cidade. Estimulados pela ideia de educação corporal e moral da juventude para além da escola, os clubs nas praças tinham um papel a desempenhar. Eles se tornaram um lugar real onde a juventude poderia experimentar as agruras e os prazeres salutares das competições esportivas. Nesse lugar, alguns jovens que não encontravam espaço nos clubes sociais e esportivos da cidade eram aceitos e tinham a importância de levantar sua bandeira, sua flâmula.

De fato, durante um longo período, as práticas esportivas na cidade eram organizadas, principalmente, por associações esportivas de origem alemã frequentadas pela elite porto-alegrense (MAZO, 2003). Essas práticas caracterizavam-se pelo culto do corpo e da mente, pela promoção da educação moral da juventude e da obediência às autoridades, e pela valorização da cultura teuto-brasileira. Nesse sentido, o associativismo esportivo constituiu-se um importante mecanismo de preservação da identidade étnico-cultural; pela difusão da ginástica alemã, de práticas esportivas e dos festivais de ginástica; e pela manutenção de um dialeto alemão nas comunidades teuto-brasileiras (MAZO, 2003).

As primeiras associações esportivas em Porto Alegre foram fundadas pelos teuto-brasileiros na segunda metade do século XIX, quando esse grupo migratório já havia superado a difícil fase da colonização e começava a dinamizar sua vida social (ROCHE, 1969). No período compreendido entre meados do século XIX e princípio do século $X X$, foram criadas 10 associações esportivas em Porto Alegre pela iniciativa dos teuto-brasileiros: Turnerbund (1867), Von Musterreiter ( 1885), Ruder 
Club (I 888), Ruder-Verein Germânia (1 892), Club Walhalla (1 896), Rodforvier Verein Blitz ( I 896), Deutscher Schristzen Verein ( 1897), União Velocipédica (I 899), Grêmio Foot-Ball Porto Alegrense (1 903) e Fussball Porto Alegre (I 903) (MAZO, 2003). Esse número expressivo reforça a importância das associações como sustentáculos das tradições de origem dos teuto-brasileiros na fase de adaptação ao novo país (SEYFERTH, 1990).

As exigências estabelecidas para o ingresso nas associações teuto-brasileiras eram influenciadas pelos critérios de nacionalidade alemã. Para associar-se, era necessário ser imigrante alemão ou teuto-brasileiro e pertencer à elite teuto-brasileira. As associações eram reconhecidas enquanto espaços da elite, cuja finalidade era tornar visível o lastro econômico, social e político do grupo, além da matriz cultural (SEYFERTH, 1990).

A cidade de Porto Alegre ostentava, em suas associações esportivas, equipes de clubes que, restritos a uma elite social, não davam acesso às classes menos favorecidas economicamente. Já os clubs das praças surgiram fora desse meio e logo conquistaram expressão esportiva. A participação dos clubs das praças na Liga Atlética Rio Grandense era uma forma de dar lugar a esses espaços públicos e ao trabalho de preparação das equipes lá executado pelo professor Gaelzer.

A propósito da participação dos clubs nos campeonatos esportivos das praças, encontramos, no acervo do CEME/ESEF/UFRGS, uma carta reclamatória dirigida ao então Vice-Intendente Municipal em exercício, Alberto Bins, publicada no jornal Diário de Notícias. Nessa carta, uma espécie de abaixo-assinado, moradores das adjacências da Praça de Desportos Florida reclamavam do fato de o professor Gaelzer, então Diretor de Esportes da cidade, ter inscrito clubs de três praças na Liga Atlética Rio Grandense, para participarem do campeonato oficial de basquetebol da cidade. A crítica ao Diretor amparava-se na alegação de que ele atentava contra os fins altruísticos que nortearam a criação das referidas praças. E, ainda, relatava que, ao filiar as três praças à Liga, foi realizada a inscrição de apenas 10 rapazes por club. Todavia, um grande número de rapazes que praticavam exercícios nessas praças recusou-se a atender à inscrição pelo club da praça, como podemos entender na transcrição de parte da carta datada de 19 de abril de 1928 :

[...] isto porque já têm esses rapazes os seus clubs predilectos na cidade, de cujas bandeiras são defensores. Isto não agradou ao sr. director que, em represália, não permitte que se entreguem a exercícios physicos nas praças outros rapazes sinão aquelles que por elle estão inscritos. Ordens severas s.s. dá no sentido de serem afastados os que não pertencem á turma de s.s organizada para o seu comando pessoal no campeonato de baskett-ball da cidade.[...] (Álbum Recreação Pública do acervo do CEME/ESEF/UFRGS.) 
A manifestação das ideias da população por meio de publicações em jornais afirmava-se como uma forma de participação nas mudanças da cidade. Nesses meios de comunicação, os leitores mostravam seus pontos de vista e exigiam o apoio de seus governantes. $\bigcirc$ que se pode depreender dessa reclamatória, entre tantos pontos citados, é que se instaurava, em 1928, no segundo ano de funcionamento das Praças de Desportos em Porto Alegre, um desejo de que as praças obtivessem representatividade esportiva. O Diretor, professor Gaelzer, que guardou, junto com recortes de publicações nos jornais da época, as reclamações que recebeu, tinha o ensejo de formar nessas praças clubs que as representassem.

As restrições instauradas aos não-participantes dos clubs de praças inscritos revelam a existência de rivalidade entre estes e os clubes de Porto Alegre. Isso fica claro na expressão "já têm esses rapazes os seus clubs predilectos na cidade, de cujas bandeiras são defensores" (Álbum Recreação Pública do acervo do CEME/ ESEF/UFRGS). "Se não estão comigo, estão contra mim", já diz o ditado. É nessa perspectiva que vemos o posicionamento do Diretor das praças, ao entender que os rapazes que já tinham seus clubes do coração deveriam defendê-los e utilizar seus próprios espaços para treinar e aprimorar suas equipes. Assim, a partir desse momento, as praças passaram a ser vistas como "clubes praças", e seus espaços ficaram restritos aos seus defensores.

Seguindo a noção de representação de Roger Chartier ( $199 \mid$ ), o pertencer ao club da praça, defender sua flâmula e treinar exclusivamente no seu espaço são, então, práticas culturais que estariam ligadas à representação cultural de identificação com esse club. Entendemos que a cultura é uma construção que envolve intenção racional e não resulta de atos instintivos, mas de atos e valores significativos para um grupo. Por meio destes é que se pode depreender a intencionalidade de quem os produz.

Não tardou para que os fins a que se destinavam as praças fossem comentados, e que o procedimento adotado pelo professor Gaelzer fosse criticado. A carta ainda apresentava nove solicitações relacionadas a obras, aparelhagem e material, horários de funcionamento das praças e atenção mais eficaz do Diretor. Desses, cinco pontos chamaram-nos mais a atenção e ressaltamos a seguir:

[... $2^{\circ}$. - Prohibição terminante da praça ser filiada a entidade official de athletismo, visto que a esta devem interessar somente os clubs e associações organizadas da cidade e não os jardins de recreio;

$3^{\circ}$. - Instituição dos campeonatos dos jardins de recreio, de volley-ball e basket-ball, entre os diversos pequenos clubs existentes nas praças, apurando-se annualmente o campeão de cada uma dellas em cada elemento e por fim, em provas finaes, os campeões de todos, como no anno passado, foi feito com excellente sucesso quanto ao volley-ball; 
$4^{\circ}$. - Liberdade aos clubsinhos das praças para frequentare-na como direito, sem as odiosas preferências impostas pelo sr. director;

5․ - Ser a praça aberta três vezes por semana a noite, para exercícios dos rapazes, determinando-se uma noite para cada um dos seus clubs;

$6^{\circ}$. - Um regulamento para a praça, dando direitos e deveres iguaes a todos;[...]

(Álbum Recreação Pública do acervo do CEME/ESEF/UFRGS)

Esses pontos estão entrelaçados no que vimos pesquisando, que é a clara formação de clubs nas Praças de Desportos para além dos clubes esportivos que já existiam na capital. Com essas solicitações, os reclamantes apontam para uma situação que se desenhava nas competições entre as associações esportivas e os clubs das praças. Entendemos que já se havia instaurado nas praças, naquele momento, um proceder muito semelhante aos dos clubes de fato, quando da seleção das equipes e da proibição de participação dos atletas pertencentes a outros clubes.

$\mathrm{Na}$ visão dos reclamantes, o ideal seria a realização de campeonatos entre praças, sagrando-se campeãs das competições equipes que nelas fossem formadas; e, principalmente, que os "clubsinhos" tivessem liberdade para frequentar e utilizar os equipamentos da praça. $\bigcirc$ que podemos constatar é que, mesmo após essa reclamação formal veiculada no jornal da cidade, os campeonatos e torneios nas praças multiplicavam-se. Encontramos várias notas de jornais registrando o excelente desempenho dos rapazes da Praça A ou das senhoritas da Praça B nas competições.

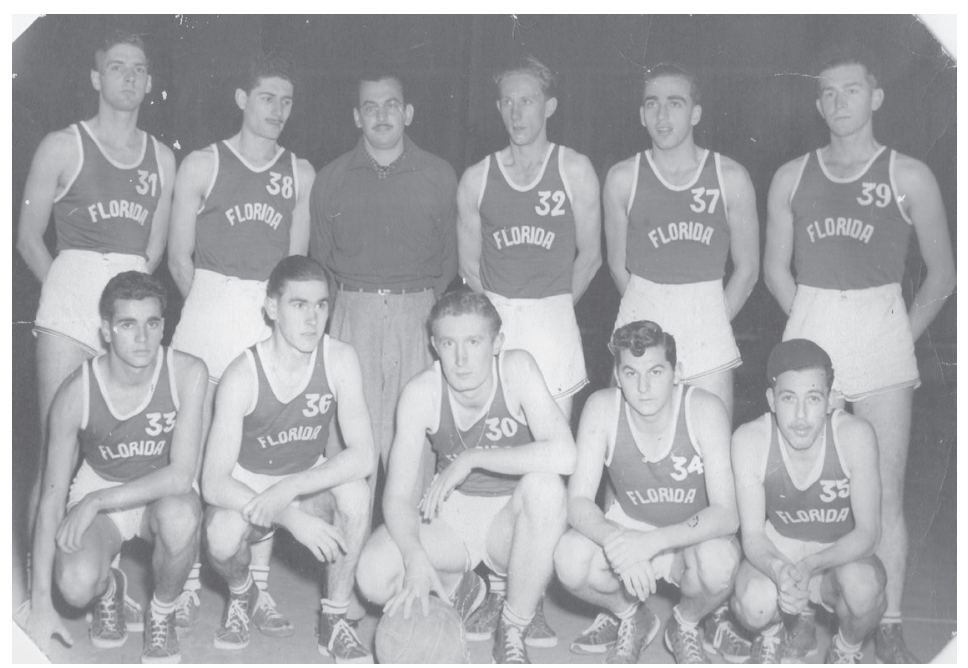

llustração 5. Equipe do Florida Atlético Clube, Praça Florida.

Fonte: Acervo do CEME/ESEF/UFRGS Álbum Recreação Pública. 
Ao final da década de 1940, o Serviço de Educação Física da Diretoria de Praças e Jardins já contabilizava a promoção de diversas competições esportivas, entre elas as de basquetebol (categorias infantil e juvenil masculino), lance livre (categorias infantil e juvenil masculino), voleibol (categorias infantil, juvenil, masculino e feminino), criquet (categoria juvenil feminino) e regata de veleiros em miniatura, nas praças da cidade. Algumas praças demonstravam um desempenho acima da média e, por isso, sagravam-se vencedoras e recebiam atenção especial nas folhas dos jornais da cidade. As praças Bartolomeu de Gusmão (conhecida como Praça Florida), Pinheiro Machado e General Osório conquistaram lugar de destaque no cenário esportivo da cidade. A Florida, localizada na zona norte da capital, teve uma movimentação esportiva intensa e representatividade expressiva em participações nos campeonatos interpraças, organizados pela Prefeitura Municipal de Porto Alegre. Tal condição permitiu que, em 1948, o club dessa praça fosse filiado à Federação Atlética do Rio Grande do Sul e, assim, pudesse disputar o campeonato citadino nas suas diversas categorias, com o nome de Florida Atlético Clube.

O desempenho de algumas equipes das praças nas competições fez com que os chamados "olheiros" circulassem pelas praças em busca de novos atletas para suas equipes. $\bigcirc$ Grêmio Foot-Ball Porto Alegrense e o Sport Club Internacional são exemplos de clubes que enviavam "olheiros" às praças. Tal fato permite verificarmos o quanto era comum, nesse período, a iniciação dos jogadores nos clubs das praças e, posteriormente a esse aprendizado, o seguimento da carreira em clubes de renome na cidade. Pode-se depreender, do depoimento de Paulo Dreyssig, jogador e treinador das equipes da Praça Florida, o significado do club da praça em relação às associações esportivas, quando diz: "Éramos um clubezinho, que não tinha nem sede, a sede era na própria praça” (DREYSSIG, 2003).

\section{CONSIDERAÇÕES FINAIS}

Os discursos proferidos para que ocorresse a instituição dos clubs das praças, ao dizerem mais do que aquilo que enunciavam, carregavam sentidos ocultos que, construídos social e historicamente, se internalizavam no inconsciente coletivo como naturais. A formação dos clubs como equipes que representavam e defendiam as flâmulas de suas praças como se, em verdade, clubes fossem nos possibilita trazer, de maneira especial, o que essas organizações representavam.

Num primeiro olhar, chamou-nos a atenção a similaridade desses clubs com as estruturas vigentes nas associações esportivas. Os clubs das praças constituídos por diretoria registrada nas folhas da cidade e por equipes inscritas nas Ligas, e com 
participação em campeonatos municipais, tornavam-se ou desejavam ser semelhantes àquelas. São estratégias simbólicas como essas que determinam posições e relações, e que constroem, para cada classe, grupo ou meio, um ser-percebido constitutivo de sua identidade.

Os clubs das praças possuíam a representatividade de uma parcela da sociedade que, não tendo acesso às associações esportivas, eram por estes representados nas competições esportivas organizadas pelo Serviço de Recreação Pública. Afirmava-se, por meio dessa prática, a identidade social de um grupo, traduzindo suas posições e seus interesses, e descrevendo uma sociedade tal como pensavam que ela era ou como gostariam que ela fosse. $\bigcirc$ esporte como fenômeno das sociedades modernas era representativo do imaginário social e assim restituiu suas marcas mais específicas, tais como a livre iniciativa, o investimento técnico e a competitividade institucionalizada em espaços públicos, nas praças de Porto Alegre de 1920 a 1940.

\section{The Invention of Clubs in public squares of Porto Alegre (1920-1940)}

ABSTRACT: The diffusion of sport practices in public squares of the city Porto Alegre in the 1920's and the improvements carried out in these spaces in order to promote sociability and leisure had favored the invention of sport clubs in those squares. The purpose of this study is to identify how the emergence of the clubs has occurred in public squares of Porto Alegre. Document analysis revealed that the squares' clubs had constructed similar representations to the ones found in sport associations. The organization of teams, the creation of their own statues, the adoption of flammules and the participation in sport events are examples of cultural representations and practices established by the squares' clubs.

KEYWORDS: Squares anda clubs; history; sport and leisure.

La creación de los clubs en plazas públicas de la ciudad de Porto Alegre (1920-1940)

RESUMEN: La difusión de las prácticas deportivas en las plazas públicas de la ciudad de Porto Alegre en los años 1920 y las mejorías instauradas en esos espacios con vistas a promover la sociabilidad y el ocio favorecieron la creación de los clubes en las plazas. El objetivo del estudio es identificar cómo ocurrió la emergencia de los clubes en las plazas públicas de Porto Alegre. Los procedimientos metodológicos de análisis documental de las fuentes impresas revelaron que los clubes constituidos en las plazas construyeron representaciones similares a las existentes en asociaciones deportivas. La organización de equipos, la elaboración de sus estatutos, la adopción de banderas y la participación en competiciones deportivas son ejemplos de representaciones y prácticas culturales establecidas por los clubes en las plazas.

PALABRAS CLAVE: Plazas y equipos; historia; deporte y ocio. 


\section{REFERÊNCIAS}

AMARAL, S. Espaços e vivências públicas de lazer em Porto Alegre: da consolidação da ordem burguesa à busca da modernidade urbana. Revista Brasileira de Ciências do Esporte, Goiânia, v. 23, n. I, p. 109-121, set. 2001 .

AMARAL, S. Lazer/Recreação: estudos de memória na cidade de Porto Alegre - uma proposta em andamento. Licere, Belo Horizonte: Centro de Estudos de Lazer e Recreação - CELAR, Escola de Educação Fisica da UFMG, 1998. 2. ed. - v. I. set. 1998.

BARDIN, L. Análise de conteúdo. Lisboa: Edições 70, 1977.

BURKE, P. O que é história cultural? Rio de Janeiro: Jorge Zahar Ed., 2005.

CHARTIER, R. A história cultural: entre práticas e representações. Lisboa: DIFEL, 1990.

CHARTIER, R. O mundo como representação. Revista de Estudos Avançados, São Paulo, v.2, n. 5, p. 173-191, jan./abr., 1991.

CUNHA, M. As práticas corporais e esportivas nas praças e parques públicos da cidade de Porto Alegre (1920-1940). I 16 f. Dissertação (Mestrado em Ciências do Movimento Humano). Universidade Federal do Rio Grande do Sul, Porto Alegre PPGCMH/UFRGS, 2009.

DREYSSIG, P. Depoimento de Paulo Dreyssig. 2003. I 5 f. (Projeto Garimpando Memórias). Disponível em: <http://www.bibliotecadigital.ufrgs.br/da.php?nrb $=000728739 \& \mid$ oc $=2010$ $\& l=76$ bbe4089f56e463 > . Acesso em: 28 jul. 2010.

ELIAS, N.; DUNNING, E. A busca da excitação. Lisboa, Diefel, $1992 \mathrm{a}$.

ELIAS, N. A sociedade dos indivíduos. Rio de Janeiro: Zahar, $1992 \mathrm{~b}$.

FARR, R. Representações sociais: a teoria e sua história. In: GUARESCHI, P.; JOVCHELOVITCH, S. (Orgs.). Textos em representações sociais. 2. ed. Petrópolis: Vozes, 1994. p. 31-59.

FEIX, E. Lazer e cidade na Porto Alegre do início do século XX: a institucionalização da recreação pública. 108 f. Dissertação de Mestrado. (Programa de Pós-Graduação em Ciências do Movimento Humano). Universidade Federal do Rio Grande do Sul, Porto Alegre, 2003.

GAELZER, F. Álbum de recortes de artigos. CEME/ESEF/UFRGS sem ficha catalográfica. s/d.

GUTIERREZ, W. ESEF Historia Pesquisa do Prof. Washington Gutierrez. Concluída em 19.07.1971. Disponível em: <http://www.esef.ufrgs.br/historia.htm>. Acesso em: I5 Jan. 2010.

JOVCHELOVITCH, S. Vivendo a vida com os outros: Intersubjetividade, espaço público e representações sociais. In: GUARESCHI, P.; JOVCHELOVITCH, S. (Orgs.). Textos em representações sociais. 2. ed. Petrópolis: Vozes, 1994. p. 63-85. 
MAZO, J. A emergência e a expansão do associativismo desportivo em Porto Alegre (18671945): espaço de representação da identidade cultural brasileira. Porto, Portugal, 2003. 365 f. Tese (Doutorado em Ciências do Desporto) - Universidade do Porto (UP).MAZO, J. Catálogo do esporte e da Educação Física na Revista do Globo (1929-1967). CD-ROM, Porto Alegre: PUCRS, 2004.

MAZO, Janice Zarpellon. Catálogo do Esporte e da Educação Física na Revista do Globo ( 1929 1967). In: Biblioteca PUCRS. Base de dados da Revista do Globo (Literatura; Publicidade; Esporte; Educação Física). Porto Alegre: Biblioteca PUCRS, n. I , 2004. CD-ROM.

MAZO, J.; SILVA, L. Os clubes esportivos e sua participação na 'Semana da Pátria' em Porto Alegre: desfiles e competições cívico-educativas (1930/1940). Arquivos em movimento, Rio de Janeiro, v. 3, p. 67-83, Julho/Dezembro 2007. Disponível em: < http://www.eefd.ufrj. br/revista >. Acesso em: 10, Jan, 2011.

PIMENTEL, F. Aspectos gerais de Porto Alegre. Porto Alegre: Imprensa Oficial, 1945.

ROCHE, J. A colonização alemã e o Rio Grande do Sul. Porto Alegre: Globo, 1969.

SEYFERTH, G. Imigração e cultura no Brasil. Brasília: Editora da UnB, 1990.

TRIVIÑOS, A. Introdução à pesquisa em ciências sociais: a pesquisa qualitativa em educação. São Paulo: Editora Atlas, 1992.

WAGNER, W. Sócio-gênese e características das representações sociais. In A. S. P. Moreira \& D. C. Oliveira. (Orgs.), Estudos interdisciplinares de representação social. Goiânia: AB, 1998, p. 3-26.

WERNECK, C. Lazer e Estilo de Vida. In: BURGOS, Míria e PINTO, Leila Mirtes S. de M. Recreação, lazer e estilo de vida no Rio Grande do Sul: refletindo sobre algumas ações desenvolvidas na capital gaúcha no período 1926-1978. Santa Cruz do Sul: EDUNISC, 2002, p. 95- 138.

Recebido: 22 jan. 2010

Aprovado: 17 ago. 2010

Endereço para correspondência:

Maria Luisa Oliveira da Cunha Av. Cel. Lucas de Oliveira, 2588, apt. 201 Bairro Petrópolis Porto Alegre - RS CEP: $90460-000$ 